University of Windsor

Scholarship at UWindsor

8-23-2017

\title{
The effects of stimulus parameters on auditory evoked potentials of Carassius auratus
}

Jessica R. Garabon

University of Windsor

Dennis M. Higgs

University of Windsor

Follow this and additional works at: https://scholar.uwindsor.ca/biologypub

Part of the Biology Commons

\section{Recommended Citation}

Garabon, Jessica R. and Higgs, Dennis M., "The effects of stimulus parameters on auditory evoked potentials of Carassius auratus" (2017). Journal of Comparative Physiology A, 1-7.

https://scholar.uwindsor.ca/biologypub/123

This Article is brought to you for free and open access by the Department of Biological Sciences at Scholarship at UWindsor. It has been accepted for inclusion in Biological Sciences Publications by an authorized administrator of Scholarship at UWindsor. For more information, please contact scholarship@uwindsor.ca. 


\section{Journal of Comparative Physiology A \\ The effects of stimulus parameters on auditory evoked potentials of Carassius auratus --Manuscript Draft--}

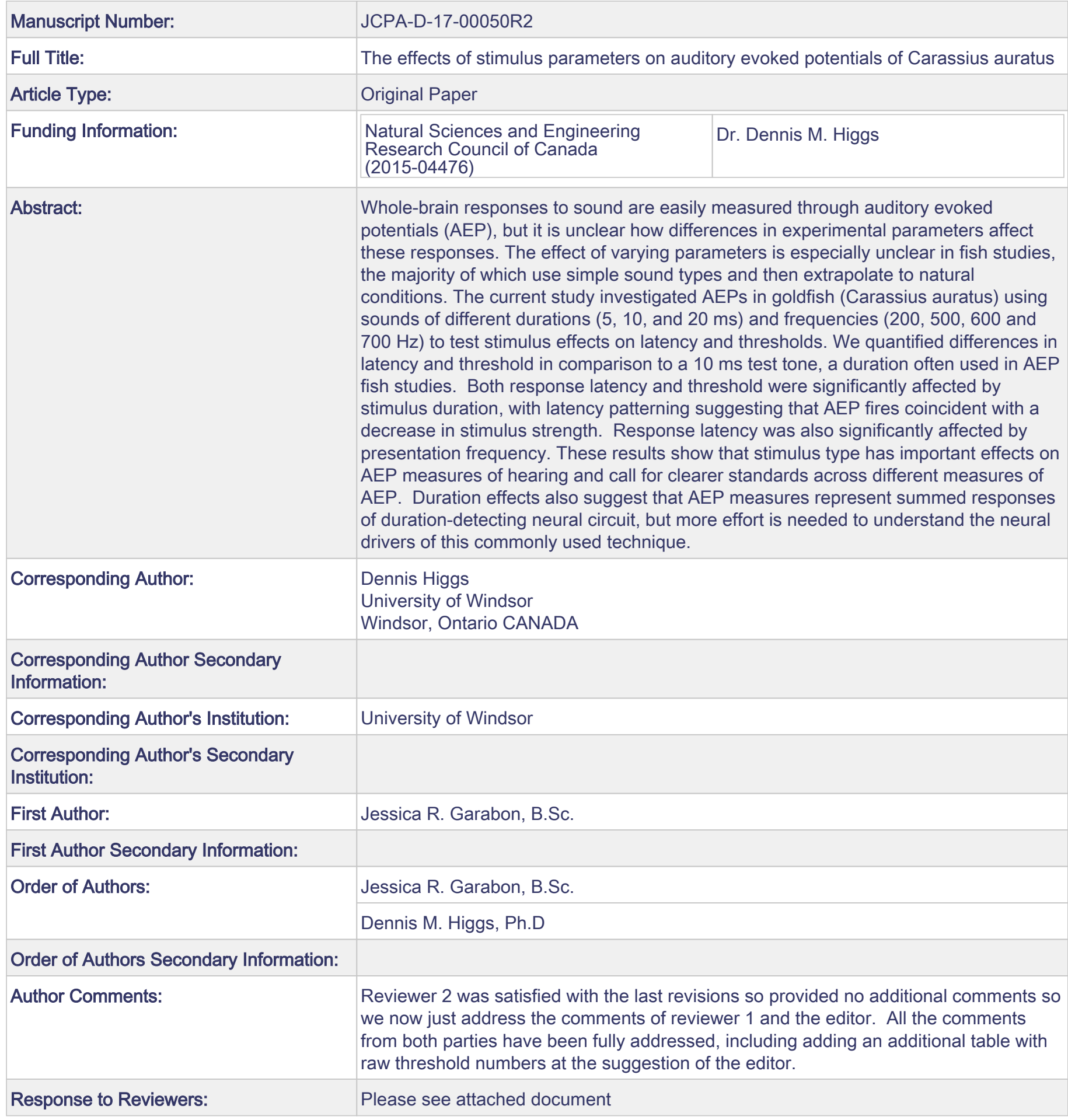




\section{The effects of stimulus parameters on auditory evoked potentials of Carassius auratus}

\section{Jessica R. Garabon • Dennis M. Higgs}

3

6 J.R. Garabon

7 Department of Biological Sciences, University of Windsor, Windsor, Canada

8 ORCID ID: orcid.org/0000-0003-2367-3788

9 D.M. Higgs

10 Department of Biological Sciences, University of Windsor

11401 Sunset Avenue, Windsor, Ontario, Canada N9B 3P4

12 E-mail: dhiggs@uwindsor.ca

13 Phone: (519) 253-3000 Ext. 4771

14

15 Fax: (519) 971-3609

16 ORCID ID: orcid.org/0000-0002-0771-4642

17

18

19

20

21

22 Acknowledgements: The authors would like to thank Craig Radford and two anonymous reviewers for comments on 23 a draft version of this work. This research was supported by Natural Sciences and Engineering Research Council 24 Discovery grant (grant \# 2015-04476).

25

26

27

28

29 30

30

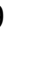

0

5

6

7

8

Keywords: Auditory evoked potential, Fish hearing, Stimulus duration, Response latency, Threshold 


\section{Abstract}

3 unclear how differences in experimental parameters affect these responses. The effect of varying parameters is

4 especially unclear in fish studies, the majority of which use simple sound types and then extrapolate to natural

5 conditions. The current study investigated AEPs in goldfish (Carassius auratus) using sounds of different durations

$6(5,10$, and $20 \mathrm{~ms})$ and frequencies $(200,500,600$ and $700 \mathrm{~Hz})$ to test stimulus effects on latency and thresholds. We

7 quantified differences in latency and threshold in comparison to a $10 \mathrm{~ms}$ test tone, a duration often used in AEP fish

8 studies. Both response latency and threshold were significantly affected by stimulus duration, with latency

9 patterning suggesting that AEP fires coincident with a decrease in stimulus strength. Response latency was also 10 significantly affected by presentation frequency. These results show that stimulus type has important effects on AEP

11 measures of hearing and call for clearer standards across different measures of AEP. Duration effects also suggest

12 that AEP measures represent summed responses of duration-detecting neural circuit, but more effort is needed to

13 understand the neural drivers of this commonly used technique.

15

6

17

8

9

0

2




\section{Introduction}

In trying to ascertain the hearing ability of a variety of fish species, one powerful technique has been the use of auditory evoked potentials (AEP). First used in 1981 (Bullock 1981), AEP has now been employed to determine baseline hearing thresholds in adult (e.g. Kenyon et al. 1998; Ladich and Fay 2013) and larval (e.g. Higgs et al. 2003; Wright et al. 2005, 2011) fish, examine the role of a variety of environmental toxins (Lu and Tomchik 2002; Low and Higgs 2014) and to assess possible effects of anthropogenic noise on fish hearing ability (Smith et al. 2004, 2006; Crovo et al. 2015). This technique is attractive because it requires no training of the study subjects (Maruska and Sisneros 2016), so AEP can quickly provide data on hearing ability without prolonged holding in a potentially noisy (Bart et al. 2001) laboratory environment, and fish can be tested repeatedly, allowing testing before and after experimental manipulation on the same fish (e.g. Wysocki et al 2009, Higgs and Radford 2013). While not appropriate for absolute threshold determination (Higgs 2002; Ladich and Fay 2013), AEP has become a wellestablished procedure among fish researchers and has provided valuable data to the field.

Despite the overall utility of the AEP approach, there still remain many unanswered questions about what AEP is actually measuring and how stimulus parameters may affect the responses recorded. By recording wholefield potentials across the brain and nerve roots, AEP is likely detecting both auditory and lateral line inputs, at least at low frequencies (Radford et al. 2012; Brack and Ramcharitar 2012; Higgs and Radford 2013), and even within a species research labs obtain very different thresholds when using AEP techniques (Ladich and Fay 2013). The actual stimuli used can also affect an individual's neural response to acoustic stimuli. For example, frequency may affect the latency of response to a given tone, as an inverse relationship between frequency and response latency has been found in zebrafish (Danio rerio) (Higgs et al. 2003), and stimulus duration has been shown to have an effect on AEPs in a range of vertebrates. For example, in the big brown bat (Eptesicus fuscus) increasing the duration of a presented tone results in an increased latency of response that ultimately correlated with the offset of the tone (Ehrlich et al. 1997). Furthermore, stimulus duration has also been shown to affect both response latency and threshold in the rat, mouse and frog (Sayegh et al. 2011). Despite these possible effects of stimulus type on auditory responses there has been little investigation of the effects of stimulus parameters on AEPs in fishes, leaving it unclear what aspects of the stimulus the fish are responding to and also how the brain may be deciphering and combining inputs to drive these responses. 
The current study investigated the effects of stimulus parameters on AEPs of goldfish, Carassius auratus.

2 Goldfish are otophysan species possessing Weberian ossicles connecting the swim bladder to the inner ear, allowing

3 relatively sensitive hearing across a broad range of frequencies (Bergeijk 1967; Higgs et al. 2006) and have become

4 an important model for auditory studies (Fay 1988, Smith et al. 2006, Higgs and Radford 2013). We aimed to

5 determine if varying auditory stimulus duration affected response latency — to better understand neural drivers

6 behind evoked potentials in fish and also how frequency affects responses across different latencies. With this

7 combination of approaches, we have attempted to begin to understand how the fish brain integrates stimuli and offer

8 suggestions for interpreting AEP results across laboratories.

9

10

11

12

13

14

15

16

17

18

19

20

21

22

23

24

56

57

58

25 26

\section{Methods}

Fish handling

Goldfish (mean \pm S.E. total length $=5.23 \pm 0.10 \mathrm{~cm}$ ) were purchased from a local commercial fish store and kept in freshwater aquaria filled with conditioned tap water and maintained at a temperature of $25.6^{\circ} \mathrm{C}$. The aquaria were held in the Central Animal Facility at the University of Windsor, with the fish maintained in accordance with the protocols set by the Animal Care Committee, and their health inspected monthly by a local veterinarian. All trials were conducted in an experimental tank (see below) filled with conditioned tap water and separate from the holding facilities. Before experiments, fish were anaesthetized by being placed in a bath of 2phenoxyethanol $\left(0.004 \mathrm{~mol} \mathrm{l}^{-1}\right)$, allowing the fish to be manipulated in the testing apparatus without movement. Use of 2-phenoxyethanol has not been evaluated for possible effects on fish sensory responses to our knowledge but since we are conducting all trial comparisons on anesthetized fish as repeated measures of threshold differences, we expect no differential effect of this anesthetic on our results. All fish were still under anesthesia effects at the conclusion of each trial. In vivo AEP measurements in response to varying stimulus durations were obtained for 30 goldfish, and each fish was tested once.

\section{Auditory evoked potential testing}

The effects of the stimulus parameters being investigated were determined using AEPs, for which the experimental protocol was modified from Radford et al. (2012). Trials were conducted in a polyvinyl chloride 
1 (PVC) tank, $1.11 \mathrm{~m}$ long with a diameter of $0.25 \mathrm{~m}$. The AEP measurements were obtained in response to sound

2 stimuli presented by an underwater speaker (UW-30, Lubell Labs Inc., www.lubell.com) which was placed $0.75 \mathrm{~m}$

3 away from the fish at the opposite end of the tank.

For each trial, the anaesthetized fish was placed on a holding apparatus consisting of a piece of sponge cut

5 lengthwise on top of a glass slide, which was adhered perpendicularly to a plastic pipette positioned within the tank

6 by a micromanipulator. The fish was placed on the sponge, with a piece of netting used to fasten the fish to the

7 apparatus. The holding apparatus was positioned within the tank using a micromanipulator and the fish was

8 submerged until its head was approximately $7 \mathrm{~cm}$ under water. Before commencement of each day of trials, sound

9 level was calibrated in the absence of fish by placing a hydrophone (Reson model LC-10; www.reson.com) in the 10 position of the fish-holding apparatus and altering the output to ensure an equal output across frequencies.

The auditory stimuli used for the trials were produced using SigGen (version 4.4) and BioSig (version 4.4)

13 System 3 apparatus. Tone bursts with frequencies of 200,500, 600, and $700 \mathrm{~Hz}$, gated through a Hanning window,

14 were delivered to each fish. For each frequency, the sound level of the tone burst was increased in $5 \mathrm{~dB}$ increments

15 until threshold was reached, at which point the tone burst was presented at $5 \mathrm{~dB}$ and $10 \mathrm{~dB}$ above threshold and the

16 AEPs recorded to examine the effects of suprathreshold sound levels. In the present research, auditory threshold was

17 defined as the minimum sound level that elicited a detectable AEP response above the background level of brain

18 activity, since visual methods provide the same thresholds as more complex analytical approaches (Mann et al.

19 2001). Stainless-steel subdermal electrodes (Rochester ElectroMedical; www. Rochestermed.com) were used to

20 gather the evoked potentials produced by the fish in response to the stimulus. The recording electrode was

21 positioned immediately posterior to the perimeter of the cerebellum, with this position being equivalent to the

22 location of the brainstem. Recording electrode placement was determined visually, as the structure of the goldfish

23 skull was visible through the translucent fish skin. The reference electrode was placed in the dorsal surface of the

24 snout region, and the ground electrode was placed under the body. For each frequency and sound level pairing, an

25 average of 400 responses were collected, with 200 responses being collected from the stimulus presentation at 90

26 degrees, and 200 responses being collected from the stimulus presentation at 270 degrees for the purpose of

27 minimizing stimulus artifacts. 
The effects of varying stimulus duration were examined by measuring AEP responses to three tone

2 durations: $5 \mathrm{~ms}, 10 \mathrm{~ms}$, or $20 \mathrm{~ms}$ ( $\mathrm{n}=10$ for each duration). As $10 \mathrm{~ms}$ tones are often used in fish AEP studies

3 (Wright et al. 2005; Smith et al. 2006; Radford et al. 2012; Higgs and Radford 2013), this duration was used as a

4 control measurement. For each fish, the first tone frequency was played at $10 \mathrm{~ms}$ and a threshold measurement was

5 taken as detailed above. Following this, the test duration (5, 10 or $20 \mathrm{~ms})$ was played at the same frequency. This

6 procedure continued for all frequencies remaining. The use of each fish as its own repeated measure control also

7 accounted for possible difference in acoustic environment between fish since they came from unknown commercial

8 provenance. The threshold values (Table 1) for the initial $10 \mathrm{~ms}$ stimulus and the test duration of interest were then

9 used to determine the absolute threshold difference to account for individual sensitivity differences between

10 individual fish. The effect of stimulus duration on latency was determined by measuring the latency of the response

11 to the auditory stimuli, with latency being defined as the time, in milliseconds, elapsed between the onset of the

12 acoustic stimulus to the onset of the AEP at $10 \mathrm{~dB}$ above threshold, as indicated by the largest declination

13 identifiable from the background.

\section{Statistical analysis}

Determination of both response latency and auditory threshold were completed visually (Brittan-Powell et 16 al. 2002), based on graphical output generated in BioSig software. A subset of the data was analyzed by three blind 17 observers to assess possible subjectivity in visual threshold measures. In all cases, thresholds were in agreement \pm 5 $18 \mathrm{~dB}$ with no clear biases across stimulus frequencies or durations. The effects of duration and frequency on both 19 latency and absolute threshold difference were determined through statistical analysis using SPSS (version 23, IBM 20 SPSS Statistics, Chicago, IL) by performing two repeated measures analysis of variances (ANOVA). Significant 21 effects were investigated further by conducting Tukey post hoc tests. A significance level of $\alpha=0.05$ was used for 22 all tests conducted.

\section{Results}

There was a significant effect of both duration and frequency of tone bursts on AEP response latency, with 25 no significant interaction between the two main effects $\left(\mathrm{F}_{6,78}=1.53, \rho=0.20\right)$. There was a significant between26 group difference for duration (Fig. $1 ; \mathrm{F}_{2,26}=18.0, \rho<0.001$ ), with Tukey post hoc analysis indicating latency was 
significantly longer at $20 \mathrm{~ms}(9.50 \pm 0.41 \mathrm{~ms})$, compared to $5 \mathrm{~ms}(6.08 \pm 0.41 \mathrm{~ms}, \rho<.001)$ and $10 \mathrm{~ms}(7.18 \pm 0.43$ $\mathrm{ms}, \rho<0.002)$ and that latency at $10 \mathrm{~ms}$ was longer than at $5 \mathrm{~ms}(\rho=0.18)$, but this did not reach statistical significance. A significant difference was also identified for frequency (Fig. $2 ; F_{3,78}=18.568, \rho<0.001$ ), where a negative relationship was identified between frequency and latency. Latency at $200 \mathrm{~Hz}(8.86 \pm 0.31 \mathrm{~ms})$ was longer than that at $500(8.03 \pm 0.28), 600(7.47 \pm 0.28)$, and $700 \mathrm{~Hz}(6.00 \pm 0.47 \mathrm{~ms})$ and $700 \mathrm{~Hz}$ had a much shorter latency than all other frequencies.

The differential presentation of both tone duration and frequency also significantly affected absolute threshold difference between presentations. There was a significant between-group difference for duration (Table 1, Fig. $3 ; F_{2,26}=7.40, \rho=0.003$ ) and Tukey post hoc analysis indicated that absolute threshold difference was significantly lower at the $10 \mathrm{~ms}(0.97 \pm 0.56)$ duration, compared to $5 \mathrm{~ms}(3.75 \pm 0.54, \rho=0.004)$ and $20 \mathrm{~ms}(3.38 \pm$ $0.54, \rho=0.013$ ), with both $5 \mathrm{~ms}$ and $20 \mathrm{~ms}$ presentations resulting in an increase in threshold as compared to $10 \mathrm{~ms} .$. Moreover, $5 \mathrm{~ms}$ and $20 \mathrm{~ms}$ were not significantly different from one another $(\rho=0.874)$. Additionally, a significant between-group difference was identified for frequency (Fig. $4 ; \mathrm{F}_{3,78}=5.62, \rho=0.002$ ), with the lowest mean difference $(1.00 \pm 0.37)$ at $700 \mathrm{~Hz}$.

In addition to this statistical analysis, response latency values were matched with the waveform of the signal. In doing this, it was determined for the $10 \mathrm{~ms}$ and $20 \mathrm{~ms}$ stimuli that the AEP response was coincident with a decrease in signal strength, due to the ramping up and down of the presented tone. Alternatively, the response for the 5 ms stimulus came after stimulus cessation (Fig 5).

\section{Discussion}

The major objective of the current research was to determine the effects that stimulus parameters, namely duration and frequency, have on the auditory evoked potentials of goldfish. Consistent with the original hypothesis, increasing the duration of auditory stimuli resulted in an increased latency of evoked potentials. If the fish were responding to the point of sound offset, as hypothesized, an increase in stimulus duration would increase the latency of response by the same duration. However, in this experiment, this one-to-one relationship was not seen. While the $10 \mathrm{~ms}$ and $20 \mathrm{~ms}$ responses were coincident with a decrease in the strength of the signal, this was not seen for the 5 ms stimulus whose average latency came after signal cessation, perhaps indicating a minimum time for acoustic stimulus processing. In amphibians and many mammals, there are populations of duration-tuned neurons (DTN) in 
mid-brain and higher areas that selectively encode different sound durations as a way to extract timing information about acoustic signals (Sayegh et al. 2011; Aubie et al. 2012). In fishes, the temporal structure of communication

3 sounds is directly encoded in the auditory midbrain (reviewed by Bass et al. 2005) and can be modeled as a simple

4 post-inhibitory rebound circuit that can directly encode stimulus duration in the $10-40 \mathrm{~ms}$ timeframe directly

5 relevant for behavioural interactions (Large and Crawford 2002). While the current technique cannot identify

6 individual neurons in the duration-dependent circuitry, AEP is a whole brain response that likely also detects ear and

7 auditory nerve inputs (Corwin et al. 1982) and will be influenced by the suite of neural drivers behind the response.

8 That we found the lowest threshold difference with our $10 \mathrm{~ms}$ test duration is, on one hand, not surprising

9 since $10 \mathrm{~ms}$ was also our pre-test duration but it does point to the need for further investigation on stimulus effects on threshold. Many research groups use AEP to test auditory thresholds and it has been noted that there are large 11 differences in threshold measures between groups, even within a single species (Higgs 2002; Ladich and Fay 2013), 12 but there are no standards within the field for stimulus parameters. Some investigators (Hawkins 1981; Fay and 13 Coombs 1983) have noted that, for behavioural trials, threshold increases with decreases in stimulus duration while 14 others (Popper 1972) have noted little relation between stimulus duration and auditory threshold. The approximate $1510 \mathrm{~dB}$ difference in threshold between AEP and behavioural threshold at low frequencies has been attributed 16 (Ladich and Fay 2013) to differences in signal duration between the two procedures with duration effects, when they 17 occur, attributed to differences in central brain processing (Fay 1985). We found a U-shaped distribution of 18 threshold differences but it would be interesting to see how this distribution might shift with different control tone 19 durations. Others (Kenyon et al. 1998) have pegged tone duration to the number of cycles present in the signal, 20 thereby varying duration between frequencies, but a simple cycle dependence would not explain our current results. 21 There were no interaction effects between latency and frequency in the current study so our duration effects were 22 truly time-dependent. It may be that $10 \mathrm{~ms}$ is the "ideal" stimulus duration for a maximal AEP response but it also 23 could be that the main driver behind these threshold differences is really the change in stimulus duration. 24 Regardless, our results clearly point to more investigation of duration effects on auditory threshold for AEP 25 measurements as we work to standardize approaches in this field. 
2003). It has been hypothesized that increased latency at lower frequencies could indicate stimulation of both

2 auditory and lateral line hair cells, as the lateral line is preferentially responsive at lower frequencies (Engelmann et

3 al. 2000). At $400 \mathrm{~Hz}$ and below then, both the hair cells in the inner ear as well as the lateral line may be stimulated

4 (Higgs and Radford 2013), resulting in a longer processing time for low frequency auditory stimuli; since processing

5 of one sensory pathway would hypothetically be easier and more rapid than multimodal processing. Future research

6 needs to be completed to provide evidence for this hypothesis. For example, the same methodology and stimulus

7 parameters employed in the current research could be replicated with the addition of lateral line ablation (Pohlmann

8 et al. 2004; Higgs and Radford 2013). If lateral line stimulation is, in fact, involved at these lower frequencies, we

9 would expect to see no effect of duration on response latency at low frequencies when it is ablated, causing the

10 stimulus to be perceived as only auditory. The changes in latency with frequency could also be related to the

11 reduced time window of sound energy with increasing frequency (Kenyon et al. 1998), although if this were the

12 sole driver of latency changes one would expect to see a more linear decrease in response latency with frequency

13 than has been reported here and in past studies.

14 The present research has thus demonstrated that stimulus duration and frequency play a crucial role in 15 evoked potential latency and absolute threshold difference in goldfish. This signifies the importance of standardizing 16 the testing parameters employed throughout research in fish audiology, as currently, there is no standard set of 17 testing parameters being used in this field of research. Standardizing the conditions under which AEP recordings are 18 taken, including stimulus parameters such as duration, will allow researchers to reliably compare results with one 19 another. It is important to note however that changes seen at the AEP level, here and in previous studies, must be 20 interpreted with caution when extrapolating to the physiological significance of these differences to fish in their 21 natural environment. Sound stimuli used in lab-based physiological experiments are, by necessity, of shorter 22 duration that the cacophony of sounds experience by fish in the wild. Even though fish AEP can respond to short23 scale temporal dynamics in conspecific sounds (Wysocki and Ladich 2003), these sounds are presented in isolation, 24 not the entire auditory scene to which it has been argued that fish evolved (Popper and Fay 1993; Fay and Popper 25 2012).

\section{Ethical approval}


1 All applicable international, national, and/or institutional guidelines for the care and use of animals were

2 followed. All procedures performed in studies involving animals were in accordance with the ethical standards of 3 the institution at which the studies were conducted.

4

5

6

7

8

23

24

25

26

27

28

29

30 
2 Aubie B, Sayegh R, Faure PA (2012) Duration tuning across vertebrates. J Neurosci 32:6373-6390. doi:

3 10.1523/JNEUROSCI.5624-11.2012

4 Bart AN, Clark J, Young J, Zohar Y (2001) Underwater ambient noise measurements in aquaculture systems: A

5 survey. Aquacult Engin 25:99-110. doi: 10.1016/S0144-8609(01)00074-7

6 Bass, A. H., Rose, G. J., and Pritz, M. B. (2005). Auditory midbrain of fish, amphibians, and reptiles: model systems

7 for understanding auditory function. In: Winer JA and Schreiner CF (eds) The inferior colliculus . Springer New

8 York. pp. 459-492.

9 Bergeijk WA (1967) The evolution of vertebrate hearing. In: Neff WD (ed) Contributions to 10 sensory physiology, vol II. Academic Press, New York, pp 1-49.

11 Brack CL, Ramcharitar J (2012) Assessment of lateral line function: A potential technique for studies in ototoxicity. 12 J Clin Neuro 19:333-335. doi: 10.1016/j.jocn.2011.06.008

13 Brittan-Powell EF, Dooling RJ, Gleich O (2002) Auditory brainstem responses in adult budgerigars (Melopsittacus 14 undulatus). J Acoust Soc Am 112:999-1008. doi: 10.1121/1.1494807

15 Bullock TH (1981) Neuroethology deserves more study of evoked responses. Neuroscience 6:1203-1215. doi: $16 \quad 10.1016 / 0306-4522(81) 90182-2$

17 Corwin JT, Bullock TH, Schweitzer J (1982) The auditory brain stem response in five vertebrate classes.

18 Electroenceph Clin Neuro 54:629-641. doi: 10.1016/0013-4694(82)90117-1

19 Crovo JA, Mendonça MT, Holt DE, Johnston CE (2015) Stress and auditory responses of the otophysan fish, 20 Cyprinella venusta, to road traffic noise. PloS One 10(9) e0137290. doi: 10.1371/journal.pone.0137290

21 Ehrlich D, Casseday JH, Covey E (1997) Neural tuning to sound duration in the inferior colliculus of the big brown 22 bat, Eptesicus fuscus. Neurophysiology 77:2360-2372. 
1 Engelmann J, Hanke W, Mogdans J, Bleckmann H (2000) Neurobiology: Hydrodynamic stimuli and the fish lateral

2 line. Nature 408:51-52. doi: 10.1038/35040706

3 Fay RR (1985) Sound intensity processing by the goldfish. Acoust Soc Am 78:1296-1309. doi: 10.1121/1.392899

$4 \quad$ Fay RR (1988) Hearing in vertebrates: A psychophysics databook. Hill-Fay Associates, Winnetka, Illinois.

5 Fay RR, Coombs SL (1983) Neural mechanisms in sound detection and temporal summation. Hear Res 10:69-92.

6 Fay RR, Popper AN (2012) Fish hearing: new perspectives from two 'senior” bioacousticians. Brain Behav Evol

7 79:215-217. doi: 10.1159/000338719.

8 Hawkins AD (1981) The hearing abilities of fish. In: Tavolga WN, Popper AN, Fay RR (eds) Hearing and sound 9 communication in fishes. Springer, New York, pp. 109-133.

10 Higgs DM (2002) Development of the fish auditory system: How do changes in auditory structure affect function?

11 Bioacoustics 12:180-182. doi: 10.1080/09524622.2002.9753688

12 Higgs DM, Radford CA (2013) The contribution of the lateral line to 'hearing' in fish. J Exp Biol 216:1484-1490. 13 doi: $10.1242 / \mathrm{jeb} .078816$

14 Higgs DM, Rollo AK, Souza MJ, Popper AN (2003) Development of form and function in peripheral auditory 15 structures of the zebrafish (Danio rerio). J Acoust Soc Am 113:1145-1154. doi: 10.1121/1.1536185

16 Kenyon TN, Ladich F, Yan HY (1998) A comparative study of hearing ability in fishes: The auditory brainstem 17 response approach. Comp Physiol A 182:307-318. doi: 10.1007/s003590050181

18 Ladich F, Fay RR (2013) Auditory evoked potential audiometry in fish. Rev Fish Biol Fisher 23:317-364. doi: $19 \quad 10.1007 / \mathrm{s} 11160-012-9297-\mathrm{z}$

20 Large EW, Crawford JD (2002) Auditory temporal computation: interval selectivity based on post-inhibitory 21 rebound. J Comp Neurosci 13:125-142. doi: 10.1023/A:1020162207511

22 Low J, Higgs DM (2014) Sublethal effects of cadmium on auditory structure and function in fathead minnows 23 (Pimephales promelas). Fish Physiol Biochem 2014:1-13. doi: 10.1007/s10695-014-9988-6 
1 Lu Z, Tomchik SM (2002) Effects of a red-tide on fish hearing. J Comp Physiol A 188:807-813. doi:

$2 \quad 10.1007 / \mathrm{s} 00359-002-0369-8$

3 Mann DA, Higgs DM, Tavolga WN, Souza MJ, Popper AN (2001) Ultrasound detection by clupeiform fishes. J

$4 \quad$ Acoust Soc Am 109:3048-3054. doi: 10.1121/1.1368406

5 Maruska KP, Sisneros JA (2016) Comparison of electrophysiological auditory measures in fishes. In: Sisneros JA

6 (ed) Fish hearing and bioacoustics, advances in experimental medicine and biology. Springer, New York, pp 227-

7254.

8 Pohlmann K, Atema J. Breithaupt T (2004) The importance of the lateral line in nocturnal predation of piscivorous 9 catfish. J Exp Biol 207:2971-2978. doi: 10.1242/jeb.01129.

10 Popper AN (1972) Auditory threshold in the goldfish (Carassius auratus) as a function of signal duration. J Acoust 11 Soc Am 52:596-602. doi: 10.1121/1.1913150

12 Popper AN, Fay RR. (1993) Sound detection and processing by fish: critical review and major research 13 questions. Brain Behav Evol 41.1: 14-25.

14 Radford CA, Montgomery JC, Caiger P, Higgs DM (2012) Pressure and particle motion detection thresholds in fish: 15 A re-examination of salient auditory cues in teleosts. J Exp Biol 215:3429-3435. doi: 10.1242/jeb.073320

16 Sayegh R, Aubie B, and Faure PA (2011) Duration tuning in the auditory midbrain of 17 echolocating and non-echolocating vertebrates. J Comp Physiol A 197:571-583. doi: 10.1007/s00359-011-0627-8

18 Sisneros JA, Popper AN, Hawkins AD, Fay RR (2016) Auditory evoked potential audiograms compared with 19 behavioural audiograms in aquatic animals. In: Popper AN, Hawkins AD (eds) The effects of noise on aquatic life 20 II. Springer, New York, pp 1049-1056

21 Smith ME, Coffin AB, Miller DL, Popper AN (2006) Anatomical and functional recovery of the goldfish (Carassius 22 auratus) ear following noise exposure. J Exp Biol 209:4193-4202. doi: 10.1242/jeb.02490

23 Smith ME, Kane AS, Popper AN (2004) Noise-induced stress response and hearing loss in goldfish (Carassius 24 auratus). J Exp Biol 207(3):427-435. doi: 10.1242/jeb.00755 
1 Wright KJ, Higgs DM, Belanger AJ, Leis JM (2005) Auditory and olfactory abilities of pre-settlement larvae and

2 post-settlement juveniles of a coral reef damselfish (Pisces: Pomacentridae). Mar Biol 147:1425-1434. doi:

$3 \quad 10.1007 / \mathrm{s} 00227-005-0028-\mathrm{z}$

4 Wright K, Higgs DM, Leis J (2011) Ontogenetic and interspecific variation in hearing ability in marine fish larvae.

$5 \quad$ Mar Ecol Prog Ser 424:1-13. doi: 10.3354/meps09004

6 Wysocki LE, Ladich F (2001) The ontogenetic development of auditory sensitivity, vocalization and acoustic

7 communication in the labyrinth fish Trichopsis vittata. J Comp Physiol A 187:177-187.

8 /doi.org/10.1007/s003590100186.

9 Wysocki LE, Ladich F (2002) Can fishes resolve temporal characteristics of sounds? New insights using auditory 10 brainstem responses. Hear Res 169:36-46. doi:10.016/S0378-5955(02)00336-2.

11 Wysocki LE, Ladich F (2003) The representation of conspecific sounds in the auditory brainstem of teleost fishes. J 12 Exp Biol 206:2229-2240. doi: 10.1242/jeb.00417.

13 Wysocki LE, Montey K, Popper AN. (2009) The influence of ambient temperature and thermal acclimation on 14 hearing in an eurythermal and a stenothermal otophysan fish. J Exp Biol 212:3091-3099. doi: 10.1242/jeb.033274 
Table 1: Average absolute threshold values ( \pm 1 S.E.) for each frequency at $10 \mathrm{~ms}$ control duration and each of three treatment durations.

\begin{tabular}{cccc}
\hline Frequency $(\mathrm{Hz})$ & $\begin{array}{c}\text { Control Threshold } \\
(\mathrm{dB} \text { re } 1 \mu \mathrm{Pa})\end{array}$ & $\begin{array}{c}\text { Treatment } \\
\text { Duration }(\mathrm{ms})\end{array}$ & $\begin{array}{c}\text { Treatment Threshold } \\
(\mathrm{dB} \text { re } 1 \mu \mathrm{Pa})\end{array}$ \\
\hline 200 & $117.5 \pm 3.35$ & 5 & $120.5 \pm 2.73$ \\
500 & $112.5 \pm 3.96$ & 5 & $118 \pm 3.09$ \\
600 & $129.5 \pm 3.02$ & 5 & $134 \pm 1.79$ \\
700 & $126.5 \pm 2.48$ & 5 & $128.5 \pm 1.83$ \\
200 & $117 \pm 3.51$ & 10 & $118 \pm 3.27$ \\
500 & $117.5 \pm 3.18$ & 10 & $119.5 \pm 2.83$ \\
600 & $133.33 \pm 1.93$ & 10 & $134.44 \pm 1.67$ \\
700 & $128 \pm 2.90$ & 10 & $128 \pm 2.90$ \\
200 & $121.9 \pm 2.59$ & 20 & $127.5 \pm 1.67$ \\
500 & $121.5 \pm 2.59$ & 20 & $126.5 \pm 3.34$ \\
600 & $130.5 \pm 2.63$ & 20 & $133 \pm 2.13$ \\
700 & $128 \pm 3.28$ & 20 & $129 \pm 3.00$
\end{tabular}




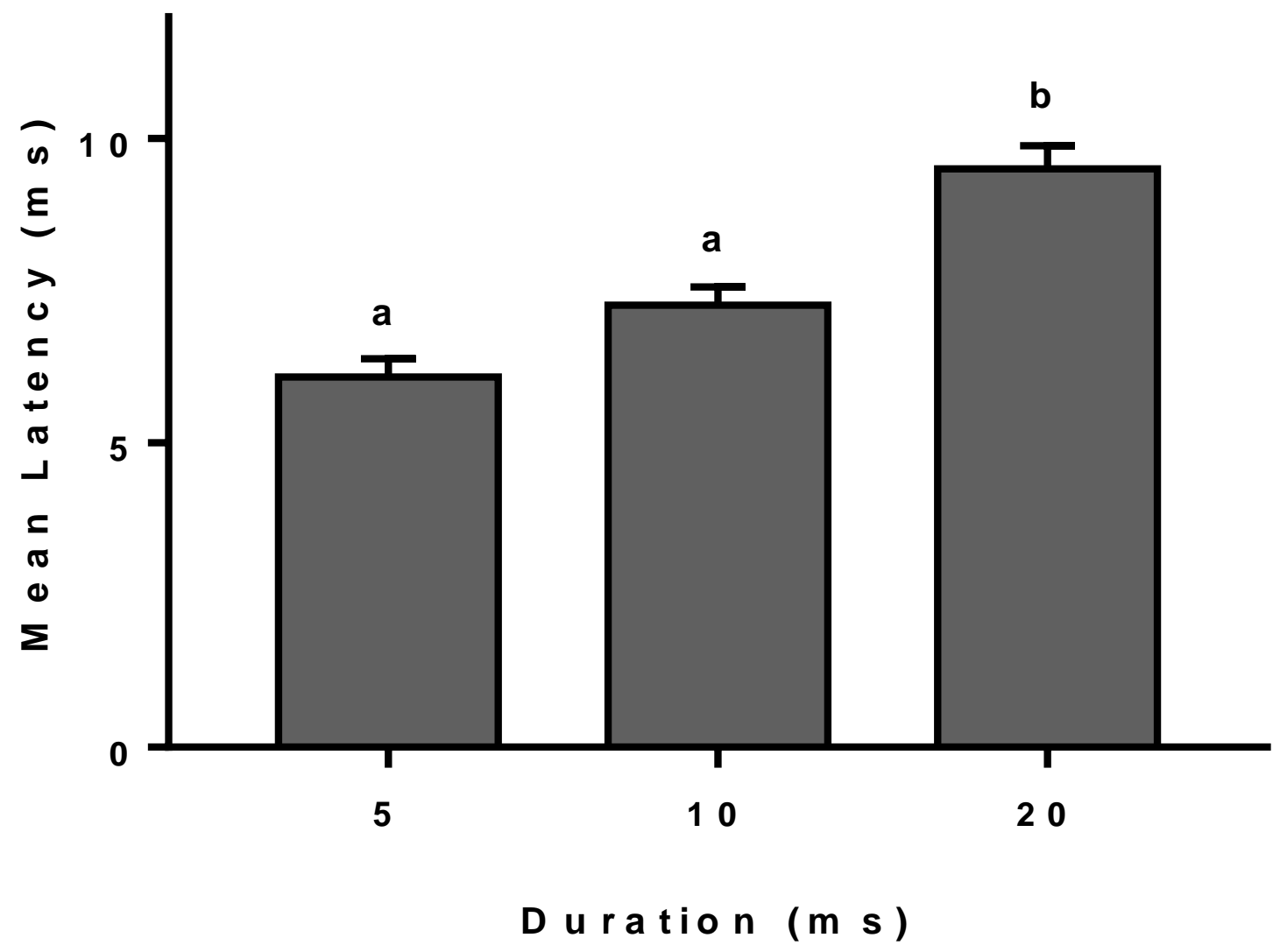

Fig. 1. Mean latency (+ 1 S.E.) values for each stimulus duration. Latency of evoked potentials increased with increasing stimulus duration. Letters "a" and "b" indicate significantly different values. Latency was significantly shorter at $5 \mathrm{~ms}(\rho<.001)$ and $10 \mathrm{~ms}(\rho=.002)$ compared to $20 \mathrm{~ms}$. No significant differences in latency were seen between 5 and $10 \mathrm{~ms}(\rho=.176)$. 


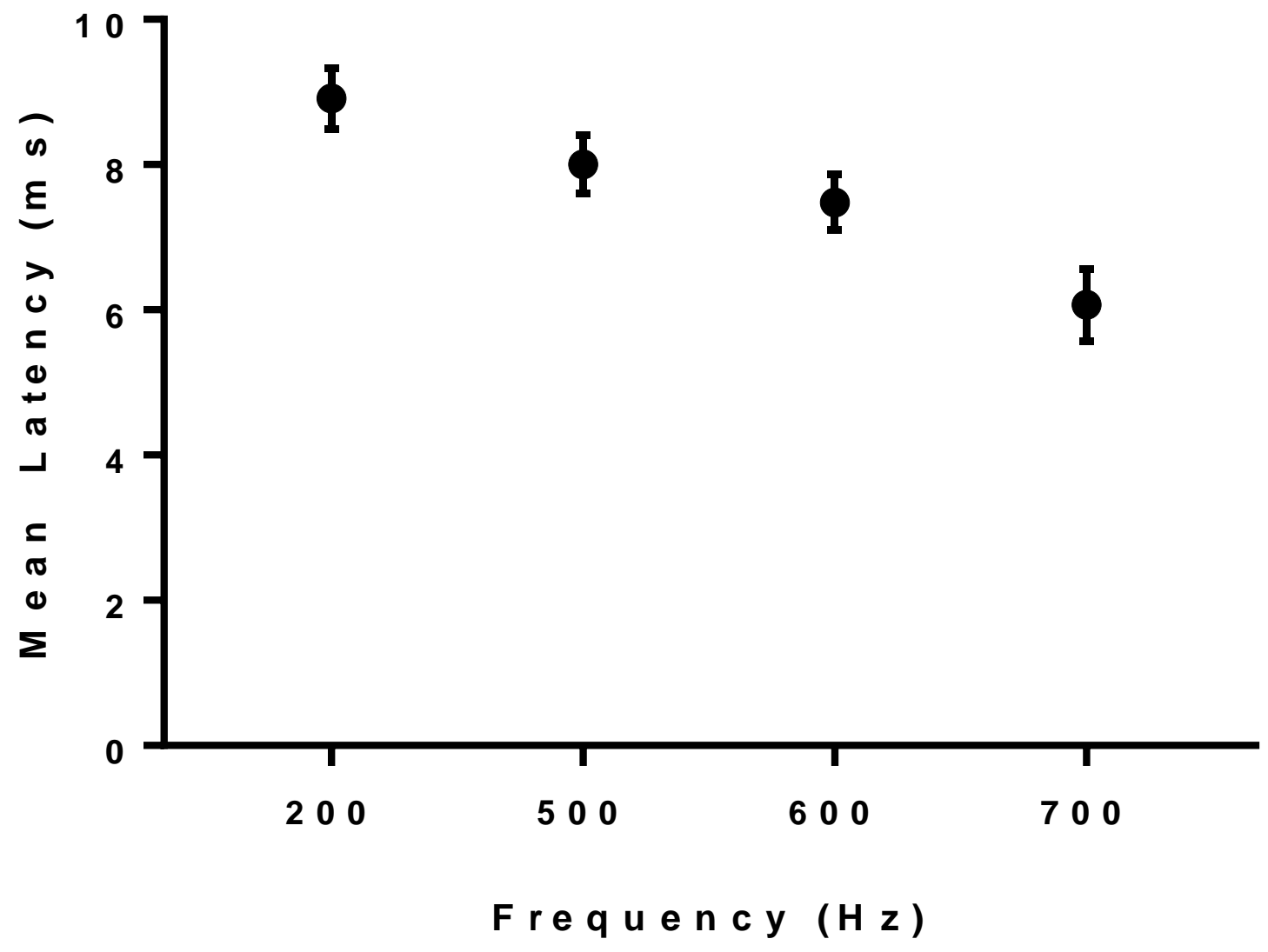

Fig. 2. Mean latency of evoked potentials in response to tone bursts of varying frequency including 200, 500, 600, and $700 \mathrm{~Hz}$. Plot displays mean latency values for each frequency with the standard error of the mean. 


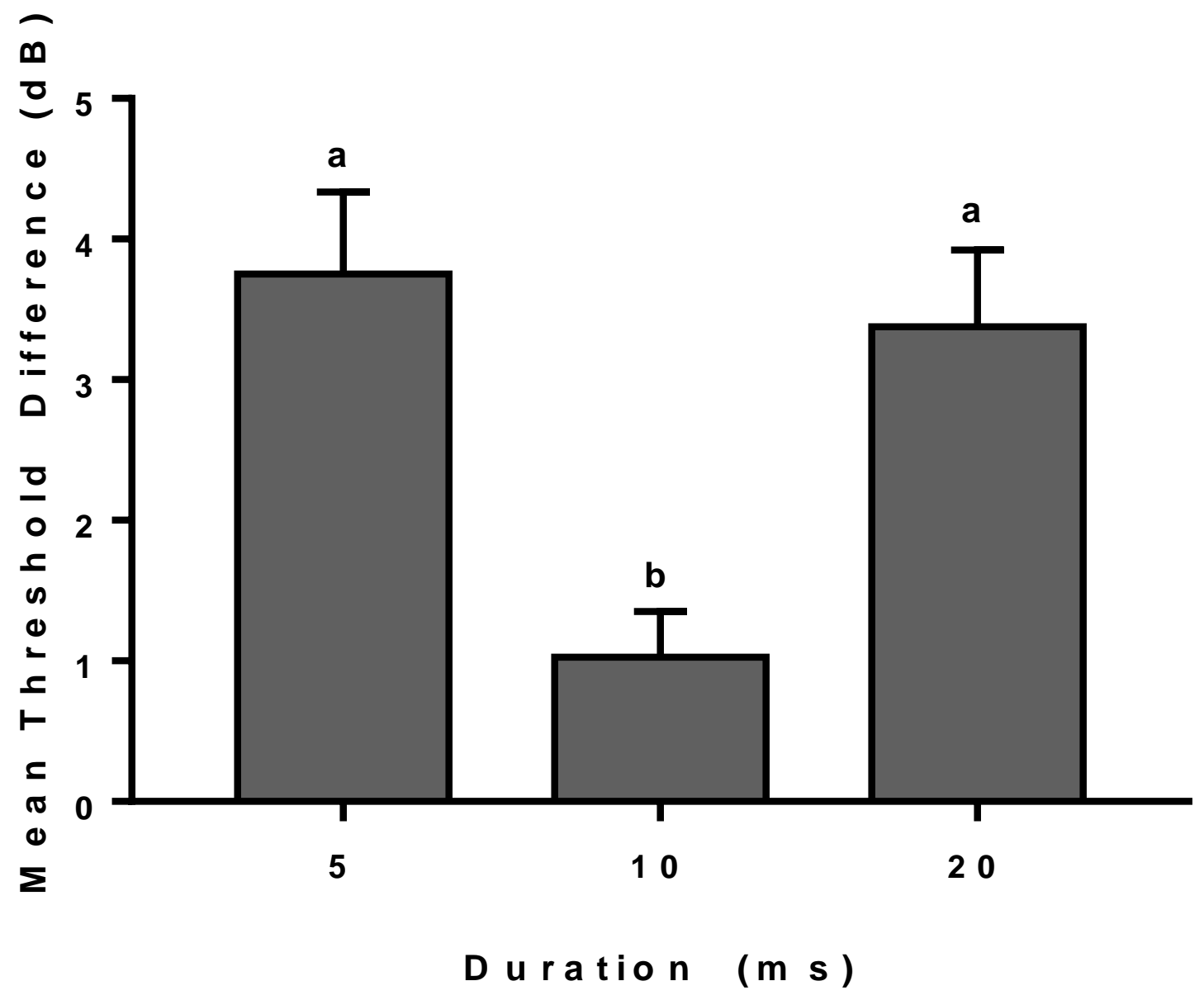

Fig. 3. Auditory threshold difference (+ 1 S.E.) in response to stimulus durations of 5, 10, and $20 \mathrm{~ms}$. Mixed effects of duration on frequency were found. Significant relationships are indicated with letters "a" and "b". There was no significant difference found between threshold at stimulus durations of 5 and $20 \mathrm{~ms}(\rho=.874)$. Threshold at $10 \mathrm{~ms}$ was found to be significantly lower than both $5 \mathrm{~ms}(\rho=.004)$ and $20 \mathrm{~ms}(\rho=.002)$. 


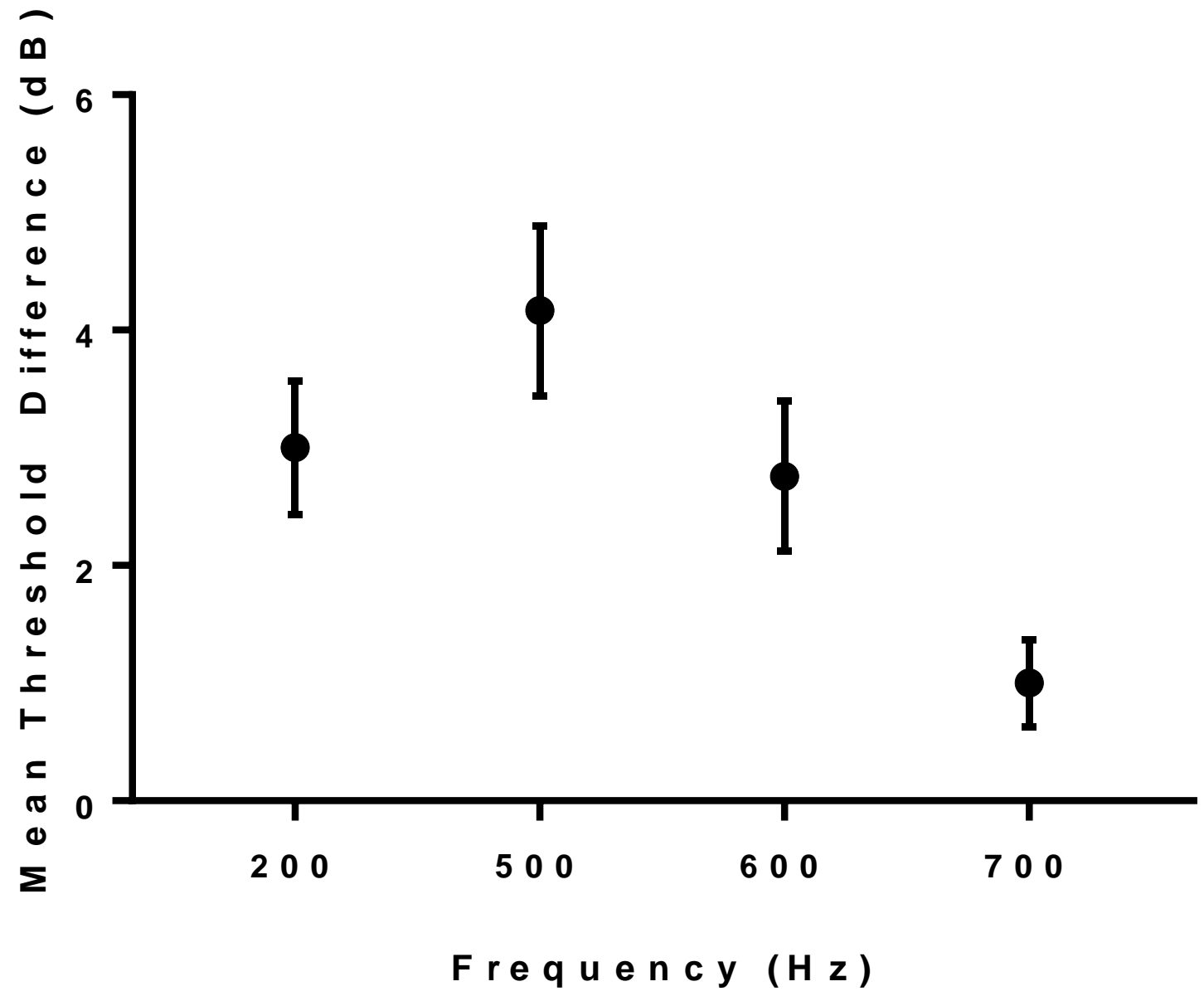

Fig. 4. Auditory threshold difference in response to tone bursts of varying frequency including $200,500,600$, and $700 \mathrm{~Hz}$. Plot displays mean threshold values for each frequency with the standard error of the mean. 

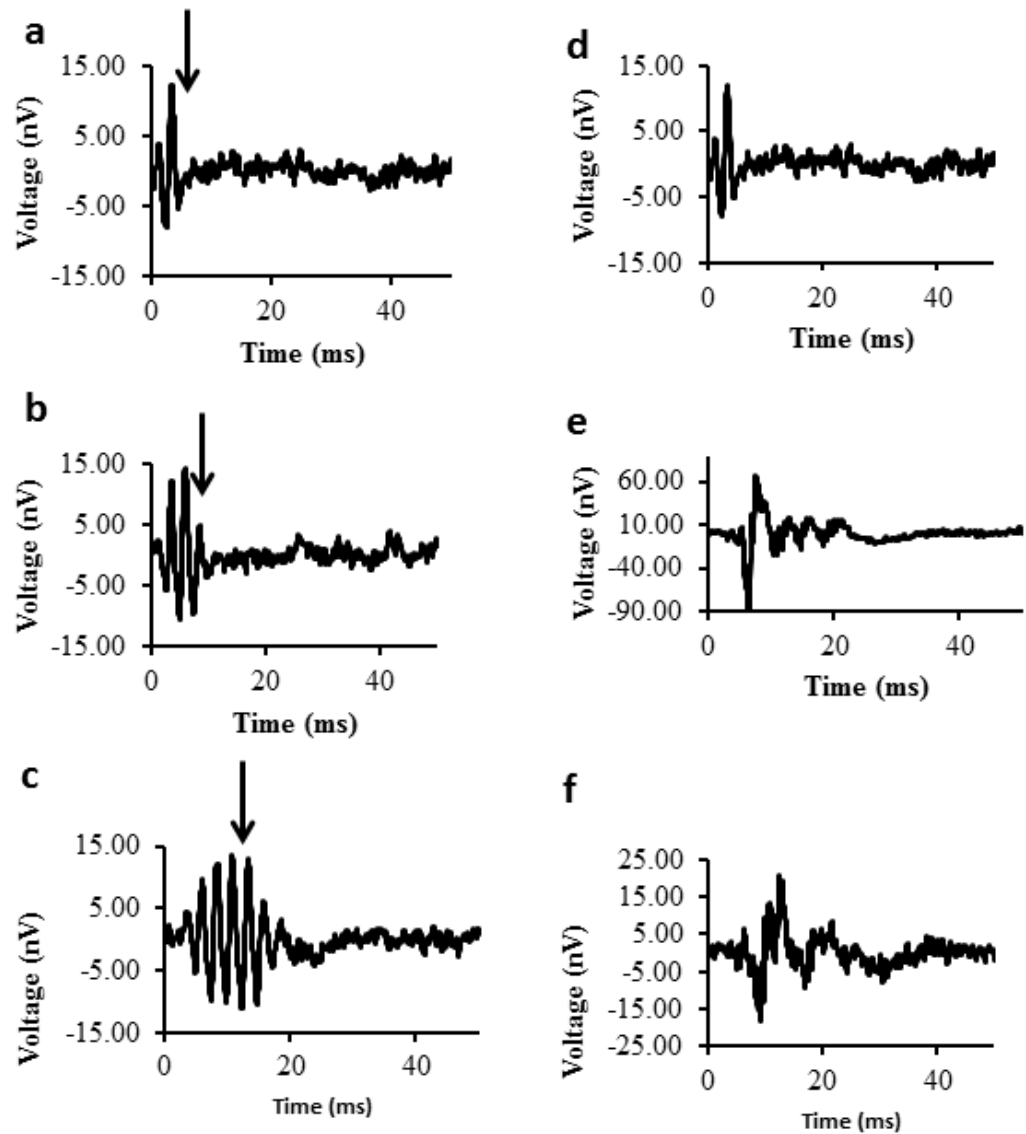

Garabon \& Higgs Fig 5

Fig. 5: Stimulus traces for $500 \mathrm{~Hz}$ as received at the fish holder for $5 \mathrm{~ms}$ (a), $10 \mathrm{~ms}$ (b), and 20 ms (c) stimulus durations and corresponding suprathreshold AEP response traces (d-f) for each stimulus condition. Arrow in a-c shows the mean location of response latency for each stimulus condition. 
Response to reviewers

COMMENTS TO THE AUTHOR:

Editor:

- please change all "\&" to "and" throughout the MS

Response: This change has been made throughout

- references in chronological order; s. p.3,I.7 and p.8,I.12

Response: This change has been made throughout the manuscript

- no upper case initials in headlines (except first word) and no abbreviations in headlines

Response: these changes have been made throughout the manuscript

- scientific genus and species names in italics: see p.11,I.13,20,22; p.12,I.15; p.13,I.21,23

Response: These corrections have been made.

- p.14,I.9: J Exp Biol

Response: this change has been made

Below, please find the reviewers' comments for your perusal.

You are kindly requested to also check the website for possible reviewer attachment(s).

Reviewer \#1: The revised manuscript has been improved to some degree but it needs further improvement.

This study intends according to the abstract to investigate the effects of sound duration on latency and threshold in order to develop "clearer standards across different measures of AEP". To achieve this goal absolute thresholds found in of the current study need to be compared to the approximately one dozen audiograms published so far. It is not sufficient to report that thresholds vary. Do longer stimuli result in higher or lower threshold? The comparison of absolute thresholds will help the reader to understand the effects of stimulus length on sensitivity measurements.

Response: The direction of the threshold difference, increasing at both 5 and $\mathbf{2 0} \mathrm{ms}$, has been made explicit in the results section. In addition, absolute threshold values are now provided in a table (Table 1), although threshold difference remains the more appropriate metric for statistical testing in our repeated measures design.

Of course, authors could discuss that absolute AEP thresholds should be treated carefully. This, however, does not devaluate comparison between thresholds. E.g. no one will question higher absolute thresholds (= lower sensitivity) in goldfish after elimination of the swim bladder or after noise exposure. I disagree that absolute thresholds have no meaning.

Additional comments

Abstract 
Line 7 and line 2 on page 6: As mentioned in my first review 10 ms test tones are NOT "commonly" used in AEP studies. Exchange the word "commonly" by "used in some labs"

Response: "Commonly" has been replaced by "often" in the abstract and on page 6 line $\mathbf{2}$ in the revised manuscript

Introduction

Line 14-15: As mentioned in my first review the AEP-technique is not just recording potentials over the brainstem but over the entire auditory pathway.

Response: text here has been changed to reflect that AEP records potential across the entire brain and incoming nerves (lines 14-15 in revised)

Fig. 5: This figure has been improved by adding AEP waveforms to the stimuli played back. However, it is strange that authors present stimuli traces and AEP waveforms of $400 \mathrm{~Hz}$ stimuli, a frequency not investigated in the current study. Please correct either the number or present waveforms at a frequency used in the current experiments.

Response: The caption was in error. All stimuli and AEP waveforms are $500 \mathrm{~Hz}$, not 400 . This has been fixed.

Discussion

Page 8, line 14: Please add that there is not simple $10 \mathrm{~dB}$ difference between behavioural and AEP thresholds in the goldfish but that the difference is frequency dependent. Thresholds are higher at lower frequencies and lower at higher frequencies according to the comparison by Ladich and Fay (2013) based on median values.

Response: This change has been made (now line 15)

Page 9, line 1: Explain the term "lower frequencies" in more detail by listing the frequencies mentioned by Higgs and Radford (2013).

Response: This change has been made (now page 9 line 3)

References

Wysocki \& Ladich (2001) and Wysocki and Ladich (2003) not cited Response: These references have been added.

Reviewer \#2: I appreciate the authors' response to my suggestions and I have no further comment I recommend publication

Response: Thank you 